\title{
OASIS SUDCALIFORNIANOS: TRANSFERENCIA CULTURAL DEL VIEJO AL NUEVO MUNDO ÁRIDOS
}

\section{SOUTH CALIFORNIAN OASES: CULTURAL TRANSFER FROM THE OLD TO THE NEW ARID WORLD}

\author{
Micheline Cariño \\ Universidad Autónoma de Baja California Sur \\ Antonio Ortega Santos' \\ Universidad de Granada
}

\section{RESUMEN}

La historia de los oasis sudcalifornianos muestra la adaptabilidad social a condiciones ambientales extremas (aislamiento, aridez e imposiciones sociopolíticas), la autosuficiencia en el manejo sustentable del agua y la tierra, y la austeridad en la producción y el consumo. Esta historia inicia con la producción del espacio misional creado por los jesuitas en los humedales convertidos en oasis y continua con su ampliación al secano, donde las comunidades rancheras practican la ganadería extensiva. La modernización de la economía local conduce los oasis hacia la extinción y condena la identidad oasiana a la desaparición. Este artículo es una reflexión de ciclo largo para explicar el éxito (y fracaso) del sistema agroecológico de los oasis en Baja California Sur.

Palabras clave: Oasis, sistemas agroecológicos, identidad oasiana, Baja California Sur.

\begin{abstract}
The history of South Californian oases shows social adaptability to extreme environmental conditions (isolation, aridity and socio-political impositions), self-sufficiency in terms of water and land management, and austerity in production and consumption. This starts with the introduction of missionary areas created by Jesuits in wetlands converted into oases, and continues with their extension into the dry lands, where ranching communities practised extensive cattle farming. The modernisation of the local economy leads to the extinction of the oases and condemns the oasis identity to disappear. This article is a long-term analysis which explains the success (and failure) of the oases agro-ecological system in South Lower California.
\end{abstract}

Keywords: Oases, agro-ecological systems, oasis identities, South Lower California.

1 Este artículo es resultado de los proyectos de investigacion Mediterranean Mountainous Landscapes: An Historical Approach to Cultural Heritage Based on Traditional Agrosystem FP7 European Government, FP7-SS-2013-2 (2014-2018); Integración del Paisaje en los procesos de planificación. Aplicación al caso andaluz". Proyectos de Excelencia, Junta de Andalucía, cód. RNM 5398 (2009-2013) y Cooperación, conflictos y equilibrios en el manejo colectivo de recursos naturales (siglos XV-XXI): Ministerio de ciencia e innovación (I+D+l) HAR2013-30732; Conocimiento, Valoración y Desarrollo Sustentable de los Oasis Sudcalifornianos, CONACYT, Código. 98464. 


\section{INTRODUCCIÓN}

La historia de los oasis sudcalifornianos muestra la adaptabilidad social a condiciones ambientales extremas de aislamiento, aridez e imposiciones sociopolíticas, desde el proceso colonizador (iniciado en 1697) hasta la construcción del estado mexicano (de finales del siglo XIX a la actualidad) (Cariño 1996, 2007, 2011). Tal capacidad adaptativa tuvo por base la autosuficiencia, lograda a través del manejo sustentable del agua y la tierra, y la austeridad, tanto en la producción como en el consumo. Esa inteligencia en la toma de decisiones sobre la gestión colectiva de los recursos naturales, dio origen a una identidad sudcaliforniana que erigió un fuerte arraigo al territorio oasiano. Éste surgió con la producción del espacio misional creado por los jesuitas en el siglo XVIII en los humedales convertidos en oasis y continuó con su ampliación al secano circundante, donde las comunidades rancheras practican la ganadería extensiva, recreando el uso del espacio y de la flora silvestre que aprendieron de los indígenas, generando un complemento indispensable e indisociable a la productividad agrícola de la zona húmeda.

Esta historia de éxito adaptativo limitado (Ortega, 2013) se truncó bien entrado el siglo XX, con la irrupción de la Revolución Verde, que reorientó la agricultura sudcaliforniana hacia cultivos alineados en los parámetros de la comercialización en mercados nacionales e internacionales. El resultado fue la pérdida de centralidad de la agricultura oasiana y la desaparición de la autosuficiencia y de la austeridad (Cariño et al, 2012). El sistema agroecológico ancestral fue sustituido por una agricultura basada en la sobrexplotación de los ecosistemas áridos (tanto de sus acuíferos, como de su suelo y flora) en los valles de la Península de Baja California que fueron roturados y abiertos a la agricultura industrial. Las consecuencias para las comunidades oasianas fueron devastadoras. Inició una tendencia hacia la emigración, en busca de educación en las ciudades y de nuevas oportunidades de empleo, tanto en la agricultura intensiva en los valles, como en la industria del turismo de masas en Los Cabos. La modernización de la economía sudcaliforniana ha trazado el camino hacia la extinción de los oasis, que será inevitable si se sigue la tendencia de abandono de la población en los oasis serranos, de urbanización turística en los oasis costeros, 
de falta de valorización de la capacidad productiva de la agricultura y la ganadería oasianas, y sobre todo del desconocimiento del potencial de sustentabilidad de la oasisidad. La desaparición de la identidad cultural oasiana significaría la pérdida de los saberes bioculturales anclados al territorio desde tiempo atrás, que demostraron durante siglos tener la capacidad de usar de manera durable los escasos recursos regionales y de tener la autonomía alimentaria necesaria para subsistir en el aislamiento y la aridez.

Este artículo explica qué son los oasis y cómo fueron transferidos del Viejo Mundo a la Península de Baja California, y de qué manera en esa aislada y árida región lograron un sincretismo cultural con profunda sabiduría ambiental. Analizamos el origen, el desarrollo, el apogeo y la decadencia de los oasis sudcalifornianos, haciendo particular énfasis en la situación de amenaza de extinción en la que se encuentran en la actualidad. Esta historia ambiental sobre la indisoluble coevolución entre tierra, agua y sociedad tiene por finalidad dar a conocer el éxito del sistema agroecológico de los oasis sudcalifornianos y las causas que lo condujeron al abandono, abogando por una revaloración de su potencial sostenible y por la urgente conservación de su cultura de la naturaleza.

\section{Los oasis y su historia en la península de Baja California}

Los oasis son paisajes bioculturales (Toledo y Barrera, 2008) fruto de complejas relaciones que las sociedades han establecido en rudas condiciones geográficas, aprovechando los escasos recursos locales para desencadenar una amplificación creciente de interacciones positivas, creando un nicho ambiental fértil y sustentable, que contrasta con su entorno hostil (Laureano, 1988). Al ser producto de un estrecho vínculo sociedad/ambiente, los oasis son sistemas socio-ambientales (Berkes y Folke, 1998) y forman parte del vasto y variado conjunto de sistemas de riego tradicional, dentro del cual su especificidad ha sido la de permitir el desarrollo de la agricultura y la ganadería en las zonas desérticas, áridas y semiáridas del planeta. Por lo tanto son también paisajes agroecológicos y han acompañado a la humanidad desde la revolución neolítica hasta la actualidad, demostrando ser portadores de una extraordinaria sustentabilidad basada en estrategias de adaptación, autosuficiencia y austeridad, tanto en sus sistemas productivos, como en la organización social y el uso de los recursos naturales.

Han implicado en todos los casos profundas transformaciones de los ecosistemas naturales, ya que los oasis han sido siempre construidos por las sociedades como una estrategia adaptativa a la aridez y al aislamiento; ya sea creando una ínsula de humedad en un mar de aridez o bien modificando los humedales que ya formaban una excepción en el medio 
árido circundante. El agua es el elemento fundamental que los origina, ésta puede provenir de un pozo, un manantial, un río, un lago, e incluso el deshielo. Este preciado y escaso líquido es transportado mediante sistemas de riego relativamente complejos, formados por acequias, canales, embalses, compuertas y esclusas; modificando radicalmente la hidrografía natural de la zona. La tierra fértil es otro componente básico del sistema de oasis, y su resguardo ante avenidas de agua, deslaves o cualquier otra eventualidad, ha requerido cambios en la litósfera de las regiones donde se construyen los oasis. El paisaje nos presenta esta modificación bajo forma de ordenadas terrazas de cultivo, pero su construcción implicó la remoción de piedras, excavaciones para modificar pendientes, el acarreo de tierra y la remoción de materiales diversos. La alteración de la biota es probablemente el mayor impacto ambiental que han tenido las regiones donde se han construido los oasis. Al ser su finalidad la producción agropecuaria, han implicado la introducción constante, y durante un largo tiempo, de diversos tipos de cultivos y de variedad de animales domésticos. Entre las especies introducidas, la más emblemática de los oasis es la palma datilera (Phoenix spp.), lo que explica porque el término palmeral es a menudo empleado como sinónimo de oasis.

La existencia de oasis también ha provocado profundas transformaciones sociales ya que requiere la sedentarización de por lo menos una parte de la sociedad, que por lo general antes tenía una vida nómada. Además las comunidades oasianas han tenido que crear instituciones que les permitan auto regular el uso de los recursos naturales de los cuales depende su reproducción social. Entre éstas, las más importantes son las instituciones de riego, que generalmente emanan de la comunidad; aunque en algunos casos pueden ser impuestas por algún poder externo. La rigurosidad de la vida en los oasis también genera una identidad particular que revela una cultura de la naturaleza en la cual la vida es reverenciada y los elementos que la permiten son profundamente respetados, y por lo tanto sabiamente usados. En otros trabajos (Cariño 2011, 2012, 2013, 2014) hemos propuesto el concepto de oasisidad para referirnos a la original cultura de la naturaleza de las sociedades oasianas. En ellas, los valores de la solidaridad, la austeridad y la autosuficiencia, son la norma naturalmente impuesta por un entorno que limita la movilidad.

Los oasis se encuentran generalmente en situaciones de aislamiento y han fungido como puertos de enlace, intercambio (biológico, comercial y cultural) y abastecimiento en las largas y peligrosas travesías del los desiertos del mundo durante milenios. En este mismo sentido, los oasis son también lugares de elevados endemismos y sitios de descanso y alimentación para las especies migratorias (especialmente las aves). Esta situación explica que 
los oasis sean en la mentalidad colectiva relacionados con zonas de refugio y amparo, de ahí su vinculación con el icono de los jardines del edén. Esta asociación de ideas proviene desde la Antigüedad, lo que explica porque en el imaginario colectivo el oasis es un paisaje naturalizado, es decir que nos es tan familiar que se llegue a considerar como si siempre hubiera existido y por lo tanto fuera natural. Sin embargo, los oasis son paisajes completamente creados por los seres humanos y por lo tanto requieren de su constante cuidado. Ese espacio

"hyperantropisado tiene un equilibrio inestable, que en todo momento debe ser restablecido por el trabajo humano. La posición estable, en el sentido termodinámico, sería el desierto. Si bien en muchos ecosistemas el hombre es un factor determinante, en el caso del oasis, es la llave maestra de una espectacular transformación del entorno. La ecuación es bastante sencilla: la ausencia del hombre (de su cultura técnica y su trabajo) implica la inexistencia del oasis" (Batesti, 2005, p.16).

Los primeros oasis son uno de los logros más perdurables de las civilizaciones antiguas, en los desiertos del norte de África (Egipto), del Medio Oriente (Mesopotamia, Persia), de India del norte y del este de China. El tránsito continuo por las diferentes rutas comerciales (de la seda y de las especies) permitieron que la cultura del oasis se expandiera en las zonas desérticas, áridas y semiáridas desde el Oriente hasta el Mediterráneo. Fue la expansión de la civilización islámica lo que permitió que esta cultura se expandiera por todo el norte de África y llegara hasta el sur de Europa, en la península lbérica. Ahí, en Elche (Valencia), permanece como un vestigio viviente el que fuera uno de los oasis más grandes de Occidente. Su vasto palmeral, su intrincado sistema de riego, la vigencia de su cultura del oasis, y el hecho de ser actualmente el único oasis europeo, justificó que en 2000 fuera incluido en la lista de Patrimonio de la Humanidad (Martínez, 2008).

En la temprana época colonial (siglos XV - XVI) probablemente la cultura del oasis era más difundida y conocida en España. Lo que explica que ésta haya sido una de las transferencias culturales que llegaron del Viejo al Nuevo Mundo en el proceso de conquista y colonización. Concretamente, esta exitosa estrategia de adaptación fue la clave maestra que permitió a los misioneros jesuitas lograr lo que numerosos expedicionarios, aventureros y conquistadores no habían podido concretar: el establecimiento colonial en la península de Baja California.

Baja California es la segunda península más largas del mundo (con $1300 \mathrm{~km}$ de longitud) y es muy esbelta (140 km de ancho en promedio). 
Se sitúa al noroeste de México y comprende dos entidades federales -Baja California y Baja California Sur- que la dividen en el paralelo $28^{\circ}$. Tiene un carácter casi insular, ya que se encuentra unida al continente sólo por $4 \%$ de su perímetro, y debido a la vastedad de los dos frentes marítimos que la conforman: el océano Pacífico - al oeste- y el golfo de California -al estepor lo que tiene un elevado grado de aislamiento.

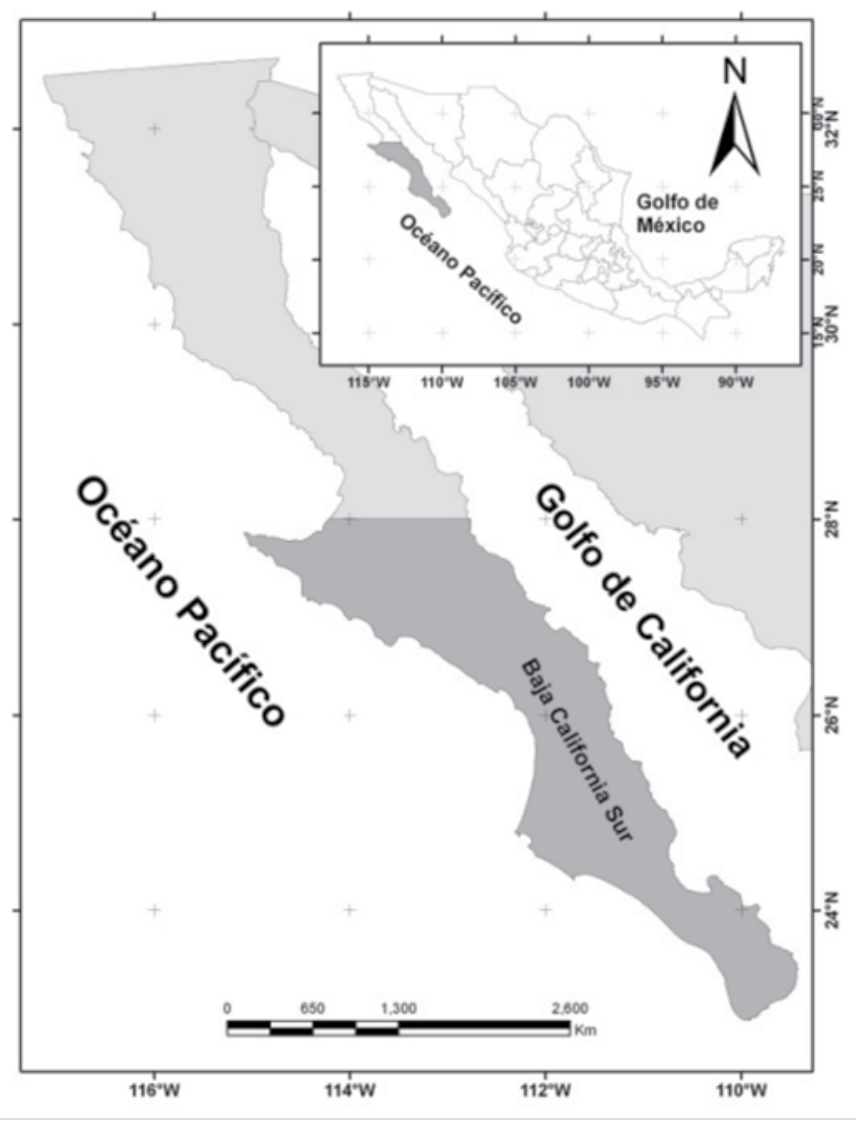

[Localización de la Península de Baja California] Elaboración propia.

La aridez es también una de las características de la mayor parte de la superficie peninsular, ya que se localiza entre las latitudes $23^{\circ} \mathrm{N}$ y $32^{\circ} \mathrm{N}$, y su porción occidental se encuentra bajo la influencia de la corriente fría de California, provocando un déficit de agua superficial y escasas precipitaciones en la mayor parte de la superficie peninsular. Sin embargo, y 
debido a su gran extensión latitudinal, se presentan diversos regímenes pluviales. En la parte norte predominan las lluvias invernales, pero en el sur es durante el verano cuando se recibe el mayor volumen de precipitación -debido principalmente a la incidencia de huracanes-, mientras que la porción central recibe la menor cantidad de precipitaciones en un régimen de lluvia biestacional. Esta variación en el sistema pluvial provoca una gran heterogeneidad en la península. Otra característica importante del territorio bajacaliforniano es la presencia de cadenas montañosas (o sierras) que corren de norte a sur, casi ininterrumpidamente, salvo por el istmo de La Paz. Las cúspides dividen la vertiente del océano Pacifico y la del golfo de California, pero la vertiente oriental es la más abrupta, y en algunos casos termina en altos acantilados costeros.

Las sierras bajacalifornianas tienen una compleja orografía recortada por profundos cañones y largas cañadas que han sido formadas por antiguas avenidas de agua y en donde se encuentran la mayor parte de los manantiales (originados por fallas y fracturas en las rocas a través de la cual brotan las aguas subterráneas) y aguas de escaza profundidad que forman los 184 humedales que han sido identificados en la península. De éstos 171 (93\%) se encuentran en Baja California Sur, 48\% de esos humedales tienen aguas superficiales y $52 \%$ sólo tienen arroyos de temporal y mezquitales (Maya et al., 1997). La presencia permanente de agua superficial permite el desarrollo de una vegetación mésica de amplia distribución como palmares, carrizos y tule. Esos humedales son también áreas de refugio para importantes especies de afinidad neártica y tropical, estaciones de reabastecimiento para especies migratorias y lugares de atracción para prácticamente todas las especies (Arriaga y Rodríguez-Estrella, 1997). Su condición de aislamiento geográfico y ecológico ha permitido la evolución de especies endémicas, particularmente de arácnidos y reptiles (Llinas y Jiménez, 2004).

La heterogeneidad ambiental de la península derivada de su gran variación latitudinal, climática, orográfica y geológica se encuentra representada también en una gran heterogeneidad de los humedales. Los hay costeros (que forman bellos esteros) y continentales (asociados a manantiales, pozas, ojos de agua, represas), y se encuentran distribuidos en forma fragmentada a lo largo de casi toda la península. En todos los casos son pequeños pues los cinco más grandes tienen una superficie promedio de $1.5 \mathrm{~km}^{2}$ (el más grande de $2.7 \mathrm{~km}^{2}$ ) y la mayoría mide menos de $0.5 \mathrm{~km}$ (Maya et al., 1997). A pesar de ser ínsulas de verdor dentro de la aridez peninsular, los humedales tienen en común la vegetación característica de estos ambientes, en la que destacan las palmas nativas (Washingtonia robusta y Erythea brandegeei), los carrizos (Phragmites communis y Arundo 
donax), los juncos (Juncus acutus) y el tule (Typha dominguensis) (Arriaga y Rodríguez-Estrella, 1997). Sin embargo, la vegetación alrededor de los humedales es muy diversa, pues depende de las variaciones latitudinales y de la influencia tropical o neártica de su localización, pero menos de la mitad fueron transformados en oasis a partir del siglo XVIII.

La península de Baja California fue descubierta en 1533 por una expedición enviada por Hernán Cortés, trece años después de la conquista de México-Tenochtitlan. El 3 de mayo de 1535, el mismo conquistador realizó por primera vez el Auto de Posesión en nombre de la Corona de España. Aunque su intención era permanecer en esa tierra a la que llamó California, al cabo de unos meses tuvo que abandonarla ya que el calor, la falta de agua y de bastimentos, más los constantes ataques de los indígenas, hicieron imposible la erección de la colonia. Una suerte semejante corrieron las expediciones que intentaron colonizar Baja California las diecisiete décadas siguientes (Cariño, 2007). Incluso en 1685 el rey Carlos II ordenó la suspensión de todas las empresas colonizadoras en California, pues la escasez de recursos naturales no justificaba los gastos. Pero la última expedición, comandada por el almirante Isidoro Atondo y Antillón y el padre Francisco Kino (1683 a 1685), sembró en los jesuitas el ardiente deseo de evangelizar a los nativos y de crear con ellos en esas inhóspitas y desprovistas tierras, un reino mariano (Cariño y Castorena, 2007).

Entre 1685 y 1697, los padres Kino y Juan María de Salvatierra lucharon por tener la autorización real para regresar a California y fundar misiones. Un requisito indispensable era la autonomía financiera, por lo que formaron el Fondo Piadoso de las Californias, lo que les permitió obtener la autorización real, pero sobre todo les concedió condiciones excepcionales al poseer la autoridad política y jurídica -además de la religiosa- en la nueva provincia. El ejercicio del poder temporal les permitió seleccionar y limitar el número de colonos y sus actividades económicas, pero también acarreo a los misioneros serios problemas y fue uno de los factores que provocó su difamación.

Con grandes esperanzas y muchas dificultades, el padre Salvatierra y un reducido número de acompañantes, el 26 de octubre de 1697, fundaron la primera misión de Las Californias dedicada a la Virgen de Loreto. Hasta su expulsión de los territorios del Imperio Español en 1768, lograron fundar en la península 18 misiones y numerosos pueblos de visita. Sabían que el principal obstáculo a vencer en la región era el agreste medio geográfico, razón por la que buscaron lugares que contaran con agua permanente, lo que en la región de manera natural solo ocurría en los más grandes humedales; además en ellos concurría abundante población indígena. Una vez que el sitio elegido era considerado factible para establecer en él una 
misión, levantaban modestas habitaciones que debían servir temporalmente como templo y refugio para el misionero y soldados. En seguida, conocedores de la experiencia mediterránea de ocupación de los territorios áridos, procedían a la construcción de un oasis, cuyo principal objetivo era la práctica agrícola. Ésta, además de permitir la producción de alimentos in situ para soldados, misioneros y colonos, era uno de los métodos más efectivos para la aculturación de los nativos, pues permitía modificar por completo su tipo de vida semi-nómada enseñándoles a ser sedentarios y nuevas formas para extraer su subsistencia del medio geográfico sin depender de la colecta y la caza.

La transformación de los humedales en oasis implicó para la Baja California la primera y una de las más drásticas transformaciones de sus ecosistemas. En los humedales más grandes transformaron la hidrografía, la litósfera y la biota. Con la introducción de las palmas datileras, a partir del siglo XVIII, se conformó en la península el paisaje cultural típico de las zonas áridas del Viejo Mundo y el espacio bajacaliforniano empezó a semejarse al de otras regiones de oasis del mundo como: el Levante español, el Magreb, el Medio Oriente, el Norte de India o el oeste de China.

Para transformar los humedales en oasis, además del conocimiento de la cultura del oasis por parte de los misioneros, se requería fuerza de trabajo. Por ello los jesuitas fomentaron la migración hacia la Antigua California de colonos laicos que se ocuparan de la construcción de la infraestructura hidráulica, así como de las labores agrícolas y ganaderas en los oasis. A partir de 1750, esos colonos empezaron a establecer sus ranchos de forma independiente de las misiones con la finalidad de abastecer a los primeros asentamientos mineros (Crosby, 1992). Esta nueva sociedad ranchera era muy poco numerosa, como lo eran los indígenas sobrevivientes a las enfermedades, las guerras y el proceso de aculturación, por lo que ambas sociedades tuvieron que convivir; ya sea que los indígenas fueran empleados en los ranchos como mano de obra o que fueran incorporados a las familias rancheras mediante el matrimonio. Así, antes de que la población indígena de la península se extinguiera por completo, logró transmitir algunos de sus ancestrales conocimientos ambientales a los rancheros. Entre éstos destaca el uso de la flora silvestre para la alimentación y con fines medicinales, así como la forma de extraer agua de plantas y lechos de arroyos, pero sobre todo, los fundamentos estratégicos de la adaptación simbiótica al ambiente característica de la cultura de la naturaleza indígena. Los principios de ésta son (Cariño, 1996):

1. Una gran economía energética: estableciendo una relación proporcional entre el gasto de energía en la obtención de alimentos y la energía que éstos les aportaban). 
2. Un uso variado e integral de la diversidad biótica: a través del consumo integral de variadas especies y el uso múltiple de sus estructuras -huesos, carapachos, pieles- para el vestido, la ornamentación y la fabricación de utensilios.

3. La preservación de los ecosistemas: evitando el agotamiento de los recursos imponiéndose una organización socio-espacial que les permitiera aprovechar los ecosistemas garantizando la recuperación natural de las especies vegetales y animales de las que dependía su subsistencia.

Se conformó de esta manera la sociedad ranchera sudcaliforniana que al optar por permanecer en la península, se le concede un papel pionero en el poblamiento civil de la Baja California. Combinando los saberes bioculturales milenarios de la cultura del oasis y de la sabiduría ambiental indígena, los rancheros desarrollaron una identidad cultural sui géneris, a la que hemos llamado oasisidad (Cariño, 2001). La capacidad adaptativa de esta cultura de la naturaleza bajacaliforniana permitió a la sociedad ranchera asegurar su reproducción social y enfrentar exitosamente el dueto mortal aislamiento/aridez. Mezclando las formas de apropiación territorial y de aprovechamiento de los recursos naturales de las dos culturas que originaron la oasisidad, los rancheros dieron una conformación territorial especial a los oasis sudcalifornianos. En ellos interactúan y se complementan los ambientes árido y húmedo, lo que nos ha llevado a replantear la configuración del sistema socio-ecológico que conforman los oasis de la Baja California.

En la zona húmeda del oasis se ubican las huertas, que en terrazas de cultivo y con sistemas de riego, lograron tener una compleja y diversa producción agrícola. Donde hacía falta tierra -ya que generalmente en los humedales sólo había arena y piedras-, ésta fue acarreada con bestias y retenida mediante la construcción de terrados; semejantes a los que aún existen en los oasis del Magreb y del Medio Oriente. Los canales de riego fueron construidos con piedra y mezcla, tallados en la roca viva, o ahuecando troncos de palmas (Baegert, 1989); a menudo fue necesario implementar esclusas, partideros y embalses. Tanto la infraestructura, como la administración de estas modestas pero vitales obras hidráulicas se asemejan a los sistemas de regadío de los oasis del Mediterráneo. Para aprovechar al máximo la limitada superficie donde era posible la práctica agrícola, se realizó una agricultura estratificada en tres niveles como sucede en otras zonas de oasis en el mundo. En el nivel superior las palmas datileras (Phoenix dactylifera) y las nativas (Washingtonia robusta y Erythea brandegeei) forman un dosel que filtra los rayos del sol, reduciendo la insolación y la evaporación. En el nivel intermedio se cultivan árboles frutales, mediterráneos y tropicales. El inferior es dedicado a la siembra de variadas 
hortalizas y de algunos granos. Además de su eficiencia ambiental, este sistema agroforestal aportaba una rica diversidad de alimentos a la población de ranchos, minas y pueblos. La práctica agrícola implicó un uso más intensivo del agua y la tierra, pero en la cultura oasiana esto no significó sobreexplotación, sino uso racional de estos recursos vitales.

En el secano se practicó la ganadería de manera extensiva, aprovechando la flora silvestre pero evitando su sobreexplotación. Los rancheros vigilaban que sus hatos se alimentaran alternando las zonas de ramoneo en el agostadero circundante de las zonas húmedas de los oasis y los conducían de un abrevadero a otro. Este sistema, llamado de cambiadero (Martínez Balboa, 1989), recuerda al pastoreo itinerante que se realiza en otras regiones áridas del mundo, pero también recrea el uso del espacio que los indígenas hacían en sus territorios de recorrido para la colecta y la caza. La complementariedad de la agricultura y la ganadería que se llevan a cabo en el territorio de la oasisidad, también se expresó en la división social del trabajo. En la agricultura trabajaban todos los miembros de la familia, mientras que en la ganadería sólo participaban los hombres recios.

La oasisidad es una relación sociedad naturaleza cuyos principios fundamentales son (Cariño, 2001):

1. Autosuficiencia: los escasos y eventuales contactos que tenían no podían ser significativos para la satisfacción de sus necesidades.

2. Austeridad, indispensable ante los límites impuestos por la fragilidad de los oasis y la rigurosidad del desierto.

3. Aprovechamiento variado e integral de la diversidad biótica, resultante de la dependencia absoluta de los limitados recursos disponibles en su territorio. La sociedad oasiana no podía darse el lujo del desperdicio, más debía conocer y respetar la capacidad de carga de los ecosistemas donde se estableció.

Con base en estas estrategias la sociedad ranchera se desarrolló permaneciendo relativamente aislada en sus oasis desde mediados del siglo XVIII hasta finales del siglo XIX. Esta situación cambió con el advenimiento del porfiriato (1875-1910), cuando la economía mexicana se encaminó hacia el capitalismo liberal, mediante la inversión extranjera y la política de concesiones territoriales y para la explotación de recursos naturales. En la Península y sus costas del Golfo de California, la extracción de cobre, plata, nácar y perlas, atrajeron la atención de grandes capitales internacionales, abriendo la región a la economía mundial (Cariño y Castorena, 2007). El territorio de los oasis no fue concesionado pero si sufrió la influencia de esa apertura. La demanda exterior (tanto nacional como extrajera) de los frutos de los oasis más grandes y productivos alteró la agricultura oasiana 
tradicional -destinada fundamentalmente al consumo local-, promoviendo su orientación hacia la comercialización. El patrón de cultivos no fue modificado ya que la producción continuó centrada en aquellos introducidos por los misioneros (caña de azúcar, cítricos, hortalizas, vid, olivo y frutales), pero los volúmenes de producción de los cultivos exportados sufrieron un incremento considerable.

Además la península de Baja California se encontraba en una situación estratégica en las rutas comerciales de altura que transitaban entre San Francisco y Panamá; La Paz fue su primer puerto de altura desde 1830. En el siglo XIX y durante el porfiriato, ese y otros puertos como San José, Loreto, Mulegé y Todos Santos, fueron importantes centros de comercialización en las numerosas rutas de cabotaje que surcaban el Golfo de California, por lo que los productos sudcalifornianos tenían amplias posibilidades de integrarse a los circuitos comerciales que ya desde entonces unían la Baja con la Alta Californias. Los cítricos sudcalifornianos tenían excelente reputación, pero su exportación a los Estados Unidos fue irregular debido a una plaga de coccídeos -Lecanium hesperidum- que se presentó en los últimos años del siglo XIX y los primeros del XX2. Para evitar este problema, así como las pérdidas por ser productos perecederos embarcados en lentas embarcaciones y en un clima caluroso, las frutas fueron exportadas bajo forma de conserva, llamadas en la región frutas pasadas. Este tipo de exportaciones regionales eran diversas e igualmente famosas, especialmente los dátiles, las uvas, las peras, los duraznos y las manzanas. Colectadas en su punto estas frutas eran asoleadas, enteras o en trozos, hasta que se evaporaba su jugo y se concentraba su azúcar. El valor de las frutas pasadas era mucho mayor que el de las frescas. La gran producción de frutas en los oasis dio origen a la industria regional de un dulce llamado ate que se fabrica mediante el cocimiento de las frutas en cacerolas de cobre con grandes cantidades de melaza.

Entre 1880 y 1940, la caña de azúcar fue el cultivo más importante (tanto en volumen como en valor) de la producción orientada al mercado exterior. Durante la década de 1880 el valor de su producción casi fue igual al de toda la producción frutícola, una pequeña parte de la producción se vendía fresca y la mayor parte se beneficiaba de forma procesada en grandes ingenios en los que se producía la panocha ${ }^{3}$, que es una forma de melaza regional. Este producto constituyó la industria agrícola más im-

2 Archivo Histórico del Estado de Baja California Sur "Pablo L. Martínez"(A.H.P.L.M.), La Paz 1900, Fomento, Vol. 300', Exp. 45.

3 AHPLM, La Paz 1898, Gobernación, Vol. 282, Exp. 82. 
portante de la región y su producción aumentó sostenidamente durante las últimas décadas del siglo XIX y las primeras del XX: en $1896^{4}$ se produjeron $679 \mathrm{tn}$, en $19105169^{5}$ tn y más de 3000 tn en el periodo comprendido entre 1918 y $1920 .^{\circ}$ El oasis de Todos Santos contribuyó constantemente con la mitad de la producción, le siguieron Santiago y San José, en el sur, así como Mulegé y San Ignacio en la media península. La decadencia de la producción de caña a partir de mediados de 1940, se debió a la sobreexplotación del agua y al agotamiento de la fertilidad del suelo en los oasis; también influyeron factores externos tales como la competencia de otras regiones del trópico húmedo, la preferencia por el azúcar refinado y la fluctuación del precio de este producto en el mercado internacional. No obstante, en 1950, la superficie cosechada apenas rebasaba las 4500 hectáreas (Urciaga, 2008), lo que representa mucho menos del uno por mil del territorio sudcaliforniano $\left(73677 \mathrm{~km}^{2}\right)$. Esto se debe a lo pequeño que es la superficie húmeda de los oasis, la agricultura a gran escala no podía realizarse en ellos y requirió la roturación de los valles y planicies costeras.

FIGURA 2

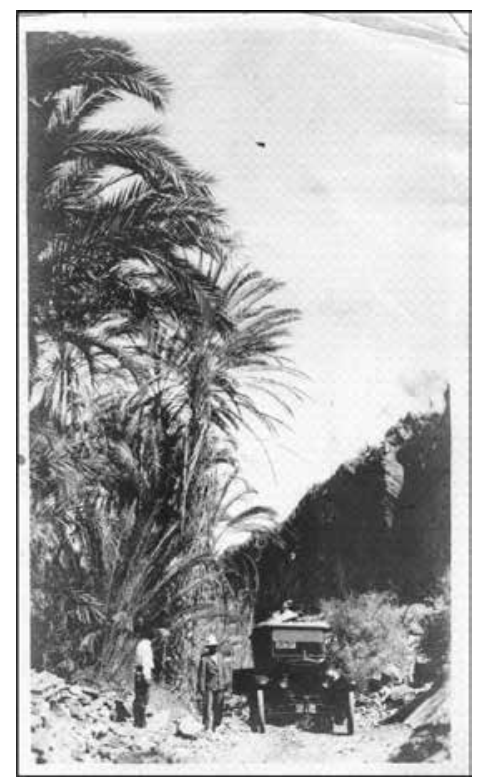

Carretera de Acceso al Oasis de los Comondú, cf. 1932. Fototeca del Estado de Baja California Sur, Legajo S/N

4 AHPLM, La Paz 1896, Fomento, Vol. 276', Exp. 12.

5 AHPLM, La Paz 1910, Fomento, Vol. 524, Exp. 32.

6 AHPLM, La Paz 1920, Gobernación, Vol. 749, Exp. 20. 
Por lo tanto, las transformaciones introducidas por el porfiriato en los oasis sudcalifornianos fueron más significativas desde el punto de vista de la cultura de la naturaleza, que desde el de la economía. La mentalidad colectiva de las sociedades rancheras de los oasis que orientaron su producción hacia la comercialización, abandonó lenta pero inexorablemente los principios de austeridad, autosuficiencia y uso racional de los recursos. Esta situación fue la sentencia de muerte de la oasisidad en esos oasis pues las aspiraciones de las familias más pudientes no se encontraban ya en los oasis, sino en las ciudades, dónde sus hijos pudieran hacer estudios superiores y tener un tipo de vida moderna. Además el éxito productivo de la agricultura comercial oasiana aportó a estas familias la riqueza suficiente para poder enviar fuera del oasis, e incluso fuera de Baja California Sur, a sus hijos, a partir de mediados de siglo XX. Cuando éstos terminaron sus estudios se instalaron en las ciudades, generalmente en la misma entidad para estar cerca de sus padres y sus terruños. El envejecimiento de la población que permaneció en los oasis fue concomitante al proceso de descentralización de su agricultura (como explicaremos en el siguiente apartado) y el abandono fue inevitablemente en aumento. Los hijos de las familias pudientes mandaron por sus ancianos padres y demás parientes, los miembros de las familias menos favorecidas tuvieron que migrar en busca de trabajo.

Actualmente, la oasisidad subsiste en unos cuantos de los oasis sudcalifornianos que han fungido como regiones refugio para la memoria biocultural (Toledo y Barrera-Bassols, 2008) sudcaliforniana. Pero desde mediados del siglo XX, las transformaciones socioeconómicas provocadas por la modernización de la economía de Baja California Sur y su integración a la globalización, agudizan el olvido de los valores de la oasisidad (Cariño et al., 2013). La mayoría de los oasis con asentamientos humanos tienen una población menor a mil habitantes, con excepción de los sitios que fueron oasis ahora convertidos en centros turísticos como San José del Cabo o Todos Santos. La mayoría de los oasis tiene servicios, equipamiento urbano y niveles de educación y salud por debajo de la media estatal, ya que son localidades aisladas, empobrecidas y abandonadas (Breceda, et al., 1997).

La decadencia de la agricultura de las huertas de los oasis inició con la irrupción de la agricultura tecnificada a través de la imposición de la Revolución Verde (desde 1950) en los amplios valles de la península y se acentuó con la producción para la exportación de hortalizas orgánicas en invernaderos desde los años 1990 (Cariño et al., 2012). El crecimiento de las ciudades como La Paz, Mulegé y Loreto, y de los centros turísticos como Los Cabos y Todos Santos, atraen a la ahora empobrecida y marginalizada población ranchera, que abandona sus oasis en busca de trabajo. Estas mismas zonas urbanas al bombear el agua de los acuíferos y manantiales 
han provocado la desecación de los oasis más cercanos. La especulación inmobiliaria ha destruido por completo los oasis costeros, como San José del Cabo. La introducción de especies invasoras vegetales (en particular Cryptostegia grandiflora) y animales es una amenaza constante y creciente a la fragilidad de la biota oasiana. Esta compleja problemática provoca que la oasisidad sea ahora, lamentablemente, una cultura en peligro de extinción.

\section{SITUACIÓN ACTUAL Y FUTURA DE LOS OASIS SUdCALIFORNIANOS: ¿DETERIORO Y EXTINCIÓN O REVALORACIÓN Y RECUPERACIÓN?}

Desde mediados del siglo XX con fuerte apoyo estatal en Baja California Sur se inició un proceso de ampliación de los regadíos, enclavados en áreas que focalizaban su producción hacia la exportación, el mejor ejemplo es el Valle de Santo Domingo, en el municipio de Comondú. Hasta los años 1980 se dispuso una ampliación hasta las 60000 ha, partiendo de algo más de 5000 ha a inicios del siglo XX. El salto energético-de cuantificable impacto negativo a largo plazo- implicó un uso no sustentable del recurso agua. En todo este período, la conversión del programa agroalimentario supuso la reducción de la producción de granos básicos y su sustitución por las hortalizas (en términos de valor del $4 \%$ al $80 \%$ en el período 1960-2006). La pérdida de cultivos básicos mermó la soberanía de los productores en aras de una llamada mercantilización-subordinación (con la herramienta de los subsidios agrarios en poder de las esferas institucionales) cuestionando sus estrategias de futuro.

Del patrón que refleja la tabla 1 , se observa el dominio de monocultivos orientados a la exportación, con el ciclo del maíz que creció de forma fluctuante desde 5000 a 22000 ha en los inicios de los años 1990. Esta producción se concentró en el municipio de Comondú (95\% del total estatal) aunque este modelo sufrió un fuerte retroceso décadas después por los altos costes de transporte y la fuerte merma de los subsidios estatales (PRONASOL, PROCAMPO). El patrón de cultivos hortofrutícolas de las huertas oasianas tuvo cierta traslación hacia el conjunto de la producción agrícola peninsular. Esta tendencia presentó divergencia y fugas dentro del patrón general de cultivo con la importancia de cultivos forrajeros e industriales (17\% superficie cosechada). Como indica Urciaga (2008), no existe una vocación productiva real de las regiones que sólo responden a impulsos puntuales y erráticos de los mercados globales. 
TABLA 1

Cultivos Algodón y Trigo, Valle Santo Domingo, 1958-1962

\begin{tabular}{|l|l|l|l|l|l|l|l|l|}
\hline \multirow{2}{*}{ Año } & Cultivo & Has & Inversión & $\begin{array}{l}\text { Valor } \\
\text { Producción }\end{array}$ & Diferencia & $\begin{array}{l}\text { Total } \\
\text { Invers. }\end{array}$ & $\begin{array}{l}\text { Total } \\
\text { Valor Prod. }\end{array}$ & Total \\
\hline \multirow{2}{*}{1958} & Algodón & 11764 & $35,292.000$ & $28,019.170$ & -7272830 & 39800.00 & 33840.37 & \\
\cline { 2 - 9 } & Trigo & 2520 & $4,308.400$ & $5,821.200$ & 1612000 & & & -5960.0 \\
\hline \multirow{2}{*}{1959} & Algodón & 3989 & 13961,500 & 15078,52 & 1116,92 & 24315,5 & 28718,42 & \\
\cline { 2 - 9 } & Trigo & 6200 & 10354.000 & 13640.0 & 3286.00 & & & 4402,29 \\
\hline \multirow{2}{*}{1960} & Algodón & 3500 & 12250.000 & 15050.000 & 2800.000 & 27614.000 & 40350.000 & 12736.000 \\
\cline { 2 - 9 } & Trigo & 9200 & 15365.000 & 25300.000 & 9936.000 & & & \\
\hline \multirow{2}{*}{1961} & Algodón & 6200 & 21000.000 & 29040.000 & 8040.000 & 46228,690 & 75569,360 & \\
\cline { 2 - 9 } & Trigo & 15107 & 25228.690 & 46529.360 & 21300.000 & & & 29340.770 \\
\hline \multirow{2}{*}{1962} & Algodón & 7500 & 26250.000 & 36300.000 & 10050.000 & & & \\
\cline { 2 - 9 } & Trigo & 18000 & 28800.000 & 55440.000 & 26640.000 & 55050.000 & 9174000 & 36690.000 \\
\hline
\end{tabular}

Fuente: A.H.P.L.M. Cuatro Años de Gobierno, 1959-62,

Anexo p. 6. Exp.131/13192

\section{TABLA 2}

Producción Agrícola en Baja California Sur 1975-1984 (Tm)

\begin{tabular}{|c|c|c|c|c|c|c|c|c|c|c|}
\hline Cultivo & 1975 & 1976 & 1977 & 1978 & 1979 & 1980 & 1981 & 1982 & 1983 & 1984 \\
\hline Alfalfa & - & - & - & 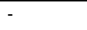 & - & - & & - & - & - \\
\hline Verde & 292896 & 282720 & 45360 & 153360 & 198000 & - & & - & - & - \\
\hline Algodón & 11787 & 11435 & 78339 & 62290 & 59320 & 4117 & & - & 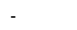 & - \\
\hline Cartamo & 260 & 20 & 67 & 663 & 7283 & 3424 & & 472 & 2380 & 3037 \\
\hline Chile Verde & 5062 & 6430 & 4800 & 10040 & 7690 & 9483 & & - & & \\
\hline Frijol & 6627 & 1416 & 1659 & 2742 & 5466 & 290 & & 6031 & 99203 & 719 \\
\hline Garbanzo & 600 & 24 & 971 & 7932 & 17096 & 1435 & & - & 15760 & 17035 \\
\hline Maíz & 6572 & 1833 & 2950 & 5154 & 4367 & 1387 & & - & 4960 & 4960 \\
\hline Grano & 1020 & 4230 & 285 & 7132 & 7470 & - & & - & 238 & 632 \\
\hline Papa & & - & - & - & - & - & & - & & - \\
\hline Sorgo & 40657 & 45052 & 2779 & 7816 & 8711 & 1805 & & 31982 & 9631 & 9222 \\
\hline Grano & 196 & 4230 & 4285 & 17220 & 42065 & 2624 & & - & 7898 & 10527 \\
\hline Tomate & 78018 & 123605 & 89070 & 106500 & 12947 & 91137 & & 140 & 99203 & 95435 \\
\hline Trigo & 142 & 3073 & 19903 & 23556 & - & 7713 & & 308 & & - \\
\hline Otros & - & - & - & - & - & - & & - & 9 & 49 \\
\hline Ajonjolí & - & - & - & - & - & - & & 472 & 351 & - \\
\hline Calabaza & - & - & - & - & - & - & & - & - & - \\
\hline Caña & - & - & - & - & - & - & & 23738 & 23 & - \\
\hline Azúcar & - & - & - & - & - & - & & - & - & - \\
\hline Algodón & - & - & - & - & - & - & & - & - & - \\
\hline Otr. Cult. & - & - & - & 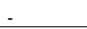 & 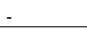 & - & & - & - & - \\
\hline
\end{tabular}

Fuente: A.H.P.L.M. Gobierno Estado BCS.INEGI. 
El sector agrícola en Baja California Sur ha sido el sustento alimentario de una población con limitado crecimiento, pero sobre todo ha suministrado a la nación mexicana materias primas a precio bajo, así como divisas para la consolidación y el crecimiento de un modelo económico exodependiente. Los problemas más recientes inciden en la baja productividad, malos sistemas de comercialización y nivel-calidad de vida de productores, con un alto nivel de explotación de los acuíferos que requiere de tecnología de riego sostenida por un alto consumo de insumos energéticos, aunque subsidiados por el gobierno federal. El patrón básico del sistema agrario en los años 1960-90 se visualiza en el predominio de los cultivos básicos (creciendo de 11000 a casi $23000 \mathrm{ha}$ ), orientados al autoconsumo y subsidio para la producción nacional, con rendimientos inferiores a 0.35 ton/ha. Los productos hortícolas tuvieron una trayectoria inversa al pasar del 1.3\% de superficie al $7 \%$, en el período considerado, aunque la participación en el valor de la producción agrícola creció más del 35\% del total (Ivanova et al, 2002).

\section{FIGURA 3}

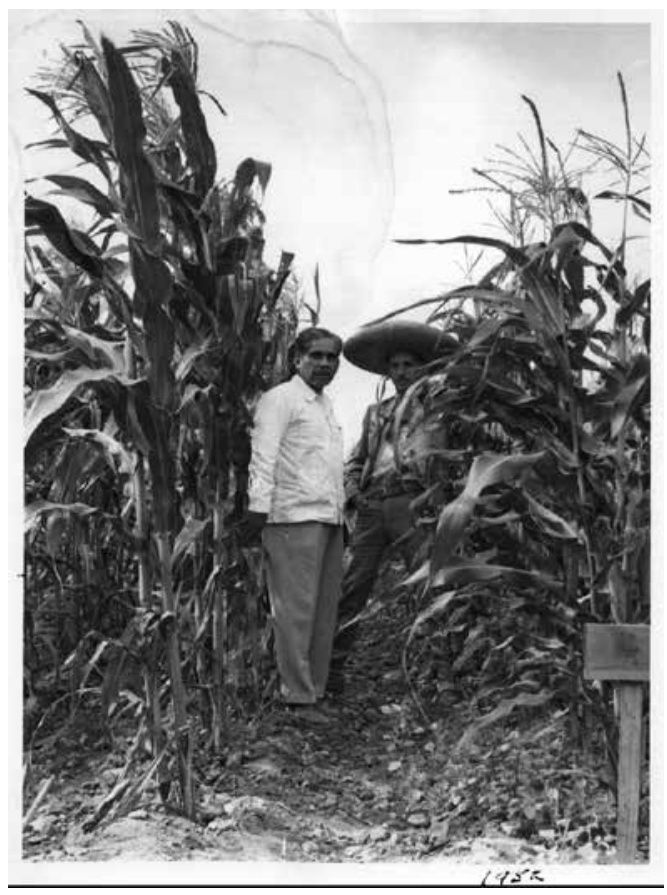

Cultivos de Maíz en Valle de Santo Domingo, cf. 1957. Fototeca del Estado de Baja California Sur. Legajo S/N. 
Este proceso define una artificialización de los agroecosistemas sudcalifornianos, con una mayor complejidad y diversificación productiva (hortalizas, forrajes, frutales y ciertos productos agrícolas). Hay una inversión con una creciente sustitución de cultivos tradicionales de exportación (algodón) y consumo interno (trigo, cártamo) por otros de exportación (garbanzo, frutales, hortalizas) y de consumo interno destinados a los usos ganaderos en expansión (sorgo, alfalfa y otros) (Ivanova et al, 2002). Estas tendencias se diversificaron tras la firma del Tratado de Libre Comercio (TLC), con un déficit comercial que entre 1992-1994 supuso más de 700 millones de dólares en agricultura y silvicultura, resuelta con la devaluación de 1994, mero espejismo del que el país salió dolorosamente en 1996. El agrosistema se convirtió en un laboratorio en el que tanto los paquetes tecnológicos, como los tejidos empresariales altamente competitivos, implementaron una política agraria volcada hacia la maximización del rendimiento económico.

\section{TABLA 3}

Unidades de Producción Rurales y Superficie Agropecuaria-Forestal Total según Municipio, 1991

\begin{tabular}{|l|c|c|c|c|c|c|}
\hline \multirow{2}{*}{ Municipio } & $\begin{array}{c}\text { Unid. } \\
\text { Producción } \\
\text { Rural }\end{array}$ & Total & De Labor & $\begin{array}{c}\text { Sólo con pasto natural, } \\
\text { agostadero o enmontada }\end{array}$ & $\begin{array}{c}\text { Con bosque o } \\
\text { selva }\end{array}$ & Sin vegetación \\
\cline { 3 - 7 } & 7342 & 2713485,389 & 99230,093 & 2493634,269 & 12745,252 & 107875,775 \\
Estado & 1563 & 212913,999 & 2463,237 & 206273,420 & 399,500 & 3777,842 \\
Cabos & 2170 & 652373,301 & 72216,195 & 578836,320 & 20,000 & 1300,786 \\
Comondú & 1115 & 1173649,498 & 8910.951 & 1066503,713 & 200,000 & 98043,834 \\
Mulegé & 2494 & 674548,591 & 15639,710 & 642020,816 & 12125,752 & 4762,313 \\
La Paz & & & & & & \\
\hline
\end{tabular}

Fuente: VII Censo Agrario Ganadero, Baja California Sur, Resultados Definitivos INEGI.7

El principal impacto ambiental de este modelo agrario es la sobreexplotación del agua, con las condiciones de excepcionalidad que antes referíamos por las condiciones climáticas, un saqueo del agua para uso agrícola con la limitada valoración ambiental del recurso. Contradicción interna al modelo, ya que junto a potenciar una protección de los acuíferos se generaban fuertes incentivos económicos para no actualizar los sistemas de regadío en un contexto de un patrón de cultivos altamente consuntivo de agua.

Entre 1960-1990 se pasó de 3 a más de 580 pozos sobreexplotados, con un $78 \%$ de pozos con incremento de salinidad. A inicios de los años 1990, el déficit de agua estaba alrededor de 87 millones de $\mathrm{m}^{3}$. Tomando

7 El término Unidad de Producción Rural se refiere al conjunto formando por: predios, terrenos o parcelas con o sin actividad agrícola, ganadera o forestal en cada municipio. 
el ejemplo del Distrito de Riego 66 del Valle de Sto. Domingo de los 704 pozos existentes, 218 estaban dañados, operan 486 y 152 presentan graves problemas de salinidad. En esta misma zona, a la altura del año 2006, solo algo más del $32 \%$ de la superficie irrigada disponía de algún sistema de riego localizado (Urciaga, 2008, p.66). En los últimos 15 años, se ha programado la reducción de extracción de agua, reequilibrando la recarga de los acuíferos (entre 1992-2006 se ha pasado de 300 millones de $\mathrm{m}^{3}$ a 167 millones).

Como se observa en la Tabla 4, de los 39 acuíferos de agua subterránea, 19 tienen 0 disponibilidad, con un promedio de déficit de -0,878444308, en tanto que los 20 acuíferos restantes presentan un promedio de disponibilidad de 0,818962795. Mediante una ecuación simple, es posible demostrar que el déficit es mayor a la disponibilidad de aguas subterráneas. ${ }^{8}$ En adición a lo anterior, la península de Baja California presenta los índices

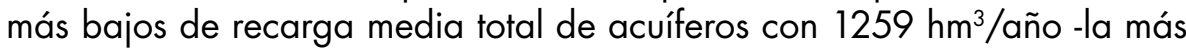
alta de México se presenta en la península de Yucatán con $25316 \mathrm{hm}^{3} / a n ̃ o$. La precipitación pluvial normal mensual que para el período 1971-2000 dio un promedio anual de $169 \mathrm{ml}$ (160 para Baja California Sur) frente al noroeste que fue de 445 y la frontera sur con 1846 (CONAGUA, 2010); además, la mayor extensión territorial donde la precipitación anual (período 1971-2000) es de 0-50 mm se encuentra en el norte de Baja California Sur, que mantuvo condiciones de sequía que oscilan entre anormalmente seco (D0) a sequía severa (D2) entre las temporadas de lluvias correspondientes al período 2008-2011. Además, los acuíferos de Mulegé. Santo Domingo, La Paz y Los Planes presentan intrusión salina (Castorena, 2014).

Este breve y muy general bosquejo de la situación del agua en Baja California Sur es fundamental para dimensionar la importancia de los oasis que constituyen junto con las escasas aguas subterráneas, el venero natural de donde manan ligeros y escurridizos arroyos la única, frágil y en peligro fuente permanente de agua, en la que fueron construidos los oasis. Retomando la reflexión inicial: los oasis fueron la huella a seguir en el proceso de conquista y colonización de la península Baja California y clave para el emplazamiento y desarrollo de las zonas urbanas que hoy sostienen la vida social, económica y cultural de Baja California Sur.

Para el cálculo de la disponibilidad de aguas subterráneas, se aplica el procedimiento de la Norma Oficial Mexicana NOM-011-CONAGUA-2000, que establece la metodología para calcular la disponibilidad media anual de las aguas nacionales, en su fracción relativa a las aguas subterráneas, menciona que la disponibilidad se determina por medio de la siguiente expresión: DAS $=R t-D N C O M-$ VCAS. DAS= Disponibilidad media anual de agua subterránea en una unidad hidrogeológica; $R t=$ Recarga total media anual; $D N C O M=$ Descarga natural comprometida; $\mathrm{VCAS}=$ Volumen de agua subterránea concesionado e inscrito en el REPDA. 


\section{TABLA 4}

Disponibilidad del agua subterránea por acuífero en Baja California Sur, situación actual

\begin{tabular}{|c|c|c|}
\hline Acuífero & Disponibilidad $^{9}$ & Déficit \\
\hline 01 Punta Eugenia & 1.377363 & 0 \\
\hline 02 Vizcaíno & 0 & -0.127523 \\
\hline 03 San Ignacio & 0 & -3.212522 \\
\hline 04 La Purísima & 0 & -2.393991 \\
\hline 05 Mezquital Seco & 1.272771 & 0 \\
\hline 06 Santo Domingo & 0.837258 & 0 \\
\hline 07 Santa Rita & 0.473646 & 0 \\
\hline 08 Las Pocitas-San Hilario & 2.142456 & 0 \\
\hline 09 El Conejo-Los Viejos & 0 & -0.374815 \\
\hline 10 Melitón Albañez & 0.935500 & 0 \\
\hline 11 La Matanza & 0 & -0.9360680 \\
\hline 12 Cañada Honda & 0.098413 & 0 \\
\hline 13 Todos Santos & 0 & -0.151039 \\
\hline 14 El Pescadero & 0.725371 & 0 \\
\hline 15 Plutarco Elías Calles & 0.22062 & 0 \\
\hline 16 Migriño & 0 & -0.03271 \\
\hline 17 Cabo San Lucas & 0 & -3.871599 \\
\hline 18 Cabo Pulmo & 0 & -0.727018 \\
\hline 19 San José Del Cabo & 0 & -5.90985 \\
\hline 20 Santiago & 4.153033 & 0 \\
\hline 21 San Bartolo & 2.972986 & 0 \\
\hline 22 El Carrizal & 3.736703 & 0 \\
\hline 23 Los Planes & 0 & -4.028117 \\
\hline $24 \mathrm{La} \mathrm{Paz}$ & 0 & -2.586662 \\
\hline 25 El Coyote & 0 & -4.724790 \\
\hline 26 Alfredo V. Bonfil & 3.690574 & 0 \\
\hline 27 Tepentú & 1.094000 & 0 \\
\hline 28 Loreto & 2.444383 & 0 \\
\hline 29 San Juan B. Londó & 0 & -2.24895 \\
\hline 30 Rosarito & 0.210680 & 0 \\
\hline 31 Bahía Concepción & 0.703975 & 0 \\
\hline 32 Mulegé & 2.016508 & 0 \\
\hline 33 San Marcos-Palo Verde & 0 & -2.175235 \\
\hline 34 San Bruno & 0 & -0.398149 \\
\hline 35 San Lucas & 0 & -0.10813 \\
\hline 36 Santa Águeda & 0 & -0.192846 \\
\hline 37 Santa Rosalía & 0 & -0.059314 \\
\hline 38 Las Vírgenes & 1.433309 & 0 \\
\hline 39 Paralelo 28 & 1.400000 & 0 \\
\hline Total de acuíferos $=39$ & $\begin{array}{l}\text { Total } \text { con disponibilidad }=20 \\
\text { Promedio disponibilidad }=0.818962795\end{array}$ & $\begin{array}{l}\text { Total con déficit }=19 \\
\text { Promedio déficit }=-0.878444308\end{array}$ \\
\hline
\end{tabular}

Fuente: http://www.conagua.gob.mx/disponibilidad.aspx? $n 1=3 \& n 2=62 \& n 3=94$ 
Basta una rápida mirada sobre la distribución y concentración de la población sudcaliforniana sobre el territorio para comprender que sobre la aridez natural, se impone el uso y abuso del agua.

Todos los acuíferos que se encuentran en el territorio sudcaliforniano están sujetos a las disposiciones del Decreto que establece el Distrito Nacional de Riego de Baja California Sur, declarando de utilidad pública la construcción de las obras que lo forman, publicado en el Diario Oficial de la Federación el 2 de julio de 1954, donde se estableció veda por tiempo indefinido para el alumbramiento de aguas del subsuelo en la región meridional del territorio de Baja California Sur. Esta veda permite extracciones limitadas para usos domésticos, industriales, de riego y otros (Ley de Aguas Nacionales, 2012).

La historia agraria sudcaliforniana muestra cómo los oasis, cuna del alumbramiento tardío de la agricultura en la región, han ido siendo desplazados hasta su estado actual en el que son relictos de la rica y diversa agrobioversidad de antaño (Cariño et al, 2013) cuyas ruinas atestiguan de lo que fuera su esplendor socioambiental. Tomemos como referente el crecimiento poblacional de la Península y comparemos con algunas de las realidades oasianas concretas. El primer momento de crecimiento se operó en el tránsito de la década de 1960 a 1970, período en el que se dio el mayor crecimiento demográfico en la historia de Baja California Sur y en el que se operó entre las décadas 1980 y 1990. El primer momento, correspondió al crecimiento de la población urbana en la ciudad de La Paz provocado por el comercio de productos extranjeros impulsado por la zona de libre comercio y de la efímera pujanza de la región agrícola del Valle de Santo Domingo.

El segundo, fue resultado del emplazamiento de la zona turística de Los Cabos, en el finis terra peninsular. En la tabla 5 se expresan las diferencias entre crecimiento absoluto y relativo por década a partir de 1930, y se observan tanto los fenómenos mencionados como la ralentización del crecimiento poblacional desde la década del 2000-2010. Por otra parte, la distribución territorial entre los cinco municipios de Baja California Sur es muy desequilibrada y todo parece indicar que así se mantendrá de continuar las tendencias antes descritas. En la actualidad, los municipios de La Paz y Los Cabos concentran $77 \%$ del total de la población, en tanto que Comondú, Mulegé y Loreto albergan el $23 \%$ restante.

9 Sólo como ejemplo para dimensionar la disponibilidad de aguas subterráneas en acuíferos donde éstas son abundantes tomé como referencia los acuíferos de Centla en Tabasco, donde la disponibilidad alcanza 828.696451 y Chicomuselo en Chiapas 700.746069. El déficit más alto del país se presenta en la zona metropolitana de la Ciudad de México con -713.629181 . 
TABLA 5

Crecimiento absoluto y relativo de la población en Baja California Sur 1930-2010

\begin{tabular}{|l|c|c|c|c|}
\hline Años & Población total & Crecimiento absoluto & Crecimiento relativo & $\begin{array}{l}\text { Diferencia del } \\
\text { crecimiento } \\
\text { Relativo por década }\end{array}$ \\
\hline 1930 & 47089 & - & - & - \\
\hline 1940 & 51471 & 4382 & 9.31 & 8.94 \\
\hline 1950 & 60864 & 9393 & 18.25 & 15.81 \\
\hline 1960 & 81594 & 20730 & 34.06 & 22.84 \\
\hline 1970 & 128019 & 46425 & 56.90 & 11.15 \\
\hline 1980 & 215139 & 87120 & 68.05 & 20.35 \\
\hline 1990 & 317764 & 102625 & 47.70 & 14.25 \\
\hline 2000 & 424041 & 106277 & 33.45 & 00.02 \\
\hline 2010 & 637026 & 212985 & 33.43 & \\
\hline \multicolumn{2}{|c|}{ 'Es la diferencia del crecimiento relativo de una década, menos el crecimiento relativo de la década anterior. } \\
\hline
\end{tabular}

Fuente: INEGI: V, VI. VII, VIII, IX, X, XI y XII Censos Generales de Población y Vivienda

Al vincular la dinámica demográfica con los acuíferos, tenemos que todos los que nutren las zonas urbanas del sur de la entidad (La Paz, Todo Santos, San José del Cabo y Cabo San Lucas) presentan 0 disponibilidad y añadir, que todos son o fueron oasis costeros que han sucumbido al peso de la urbanización y el desarrollo turístico. Hoy por hoy, Mulegé es el acuífero más importante en cuanto a disponibilidad de agua asociado a un oasis costero. La alta concentración de población, infraestructura, inversiones y servicios turísticos costeros han conducido a buscar alternativas al suministro de agua potable para uso urbano y doméstico en la desalación de agua de mar, alternativa cuyas consecuencias ambientales habrá que evaluar en el corto plazo.

En el contexto general antes descrito, a manera de ejemplo centrarnos la mirada hacia la situación concreta de un oasis, para desde un análisis micro, mostrar la crisis de estos agroecosistemas. El programa de investigación desarrollado por la Red Interdisciplinaria para el Desarrollo Integral y Sustentable de los Oasis Sudcalifornianos (RIDISOS) desde 2006, se ha concentrado en el estudio de la comunidad del oasis de Los Comondú, compuesto por los poblados San Miguel y San José (Cariño et al, 2013). El sistema tradicional de huertas de este oasis, con más de 300 años de uso sin sobreexplotar su base de recursos naturales (agua y suelo), está desapareciendo por la influencia de procesos externos, como la competencia agraria industrial que reduce la rentabilidad de la actividad productiva en 
el oasis, el despoblamiento inducido por la deslocalización sociopolítica y el relativo aislamiento en el que ha permanecido desde las últimas décadas del siglo XX, debido al trazado de la carretera transpeninsular (que lo dejó al margen) y el crecimiento de los polos de desarrollo turístico en Baja California Sur.

\section{FIGURA 4}

Tendencia Población San Miguel de Comondú

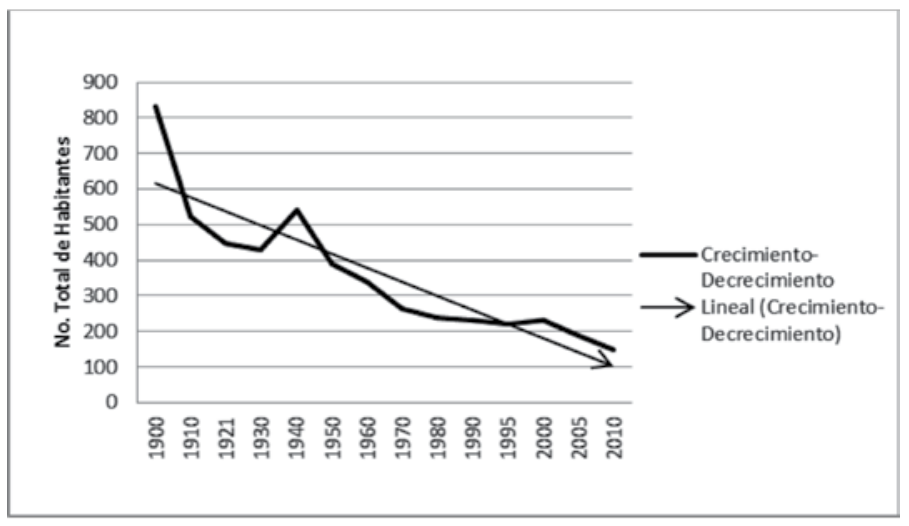

Fuente: Castorena y Martínez, 2013, p. 422.

\section{FIGURA 5}

Reconstrucción histórica de la superficie en producción (ha)

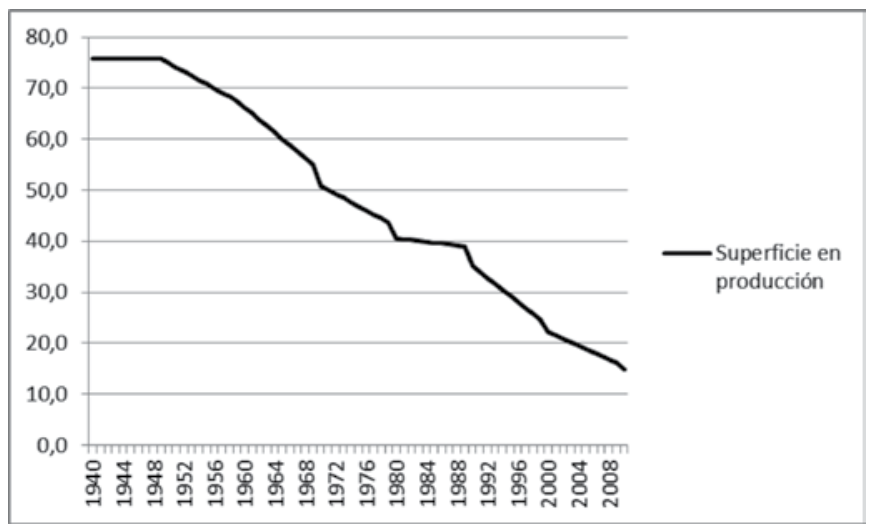

Fuente: Tenza et al., 2013, p. 376. 
El éxodo de la población en general y de los jóvenes en particular, ha disminuido enormemente la mano de obra disponible, además ha dificultado o incluso impedido que exista un proceso de reemplazo generacional en las actividades productivas. Por otro lado, la competencia agraria externa, la promoción de la ganadería caprina, la introducción de plagas vegetales y la incertidumbre en cuanto a la propiedad de la tierra dentro del oasis, son factores que han afectado profundamente a la actividad hortofrutícola tradicional. La resultante es la disminución progresiva de la superficie en producción, la desestructuración de las instituciones locales de riego y la cuasi desaparición de las tareas de limpieza y mantenimiento de las parcelas.

La RIDISOS ha explicado a los sucesivos gobiernos estatales la situación apremiante que existe en el oasis de Los Comondú, así como en todos los oasis de las sierras de La Giganta (donde se localiza Los Comondú), Guadalupe y La Laguna. En 2011, la Secretaría de Desarrollo Económico estatal formuló un proyecto estratégico llamado Oasis Sudcalifornianos en el marco de su política de desarrollo sustentable. Los miembros de la RIDISOS fuimos invitados a participar en la definición de las acciones que comprendería dicho proyecto, participamos en numerosas reuniones con funcionarios de diferentes secretarías de estado, federales y estatales, relacionadas con medio ambiente, agua, fauna, agricultura, ganadería y turismo. También impartimos cursos a los funcionarios del gobierno estatal que estarían a cargo de la intervención en campo. Sin embargo, las expectativas, los tiempos y los ritmos de los políticos son muy diferentes a los de las sociedades oasianas. Por lo tanto, muchas de las medidas tomadas por ese proyecto estratégico fueron precipitadas e incluso contraproducentes; afortunadamente el entusiasmo del gobierno por atender estos asilados nichos de identidad mermó pronto.

Las organizaciones de la sociedad civil y otros grupos de académicos también han puesto su atención en el conocimiento, valoración y conservación de los oasis sudcalifornianos. Una de las acciones más importantes ha sido el esfuerzo conjunto que desde 2007 hemos llevado a cabo la Asociación Niparaja, la Comisión Nacional de Áreas Naturales Protegidas (CONANP) y un grupo de académicos del que formamos parte, para promover la creación de la Reserva de la Biósfera Sierras Guadalupe y La Giganta, en la que se encuentra $75 \%$ de los oasis sudcalifornianos. Pero este proceso ha enfrentado severos problemas en la esfera política local y federal, ya que los actores del saqueo neoliberal y de la corrupción política son adversos a los esquemas de conservación, sustentabilidad y desarrollo social (Cariño y Monteforte, 2008).

Finalmente, y gracias al esfuerzo de investigadoras del Centro de Investigaciones Biológicas del Noroeste (CIBNOR) y de la CONANP, otra 
medida de protección para los oasis, y que sí se ha concretado, es la incorporación de ocho sistemas de humedales y oasis de Baja California Sur a la Convención Ramsar. En febrero de 2008 se decretaron como sistemas de humedales de prioridad internacional: 1) humedales de la Sierra de la Giganta, 2) humedales de La Sierra de Guadalupe, 3) humedales Mogote-Ensenada la Paz, 4) Sistema Ripario de la Cuenca y Estero San José del Cabo, 5) oasis de la Sierra del Pilar, 6) humedales Los Comondú, 7) esteros de Balandra y el Merito, y 8) cabo Pulmo. Salvo los sitios 7 y 8 que son espacios marinos, todos los demás son sistemas de oasis que se destacan a nivel mundial por sus valores ambientales y que enfrentan una urgente necesidad de medidas de conservación.

\section{Conclusión}

Los modelos de planeamiento territorial y económico del gobierno del estado de Baja California Sur y del gobierno federal mexicano, en la segunda mitad del siglo XX, promovieron un modelo de explotación agrícola de lógica agroindustrial con altos niveles de tecnificación y de consumo de inputs externos tantos energéticos como de materias primas. Éste, modelo junto al correspondiente al desarrollo turístico, fueron elementos que cuestionaron la viabilidad histórica y de futuro de la oasisidad. El abandono de las huertas, su actividad agroalimentaria incipiente y la emigración a núcleos urbanos de la región, fueron los principales efectos derivados de esa pérdida de rentabilidad. A su vez, el abandono paulatino de las huertas ha tenido consecuencias como la desestructuración de las instituciones locales de riego y el abandono de las prácticas tradicionales de manejo de suelos, y de limpieza de canales y parcelas, aumentando la vulnerabilidad socioambiental de los oasis.

Este escenario amenaza de extinción al patrimonio biocultural oasiano, el fin de sus saberes, y la desaparición de un modo de vida agrario que históricamente se ha basado en la sustentabilidad comunitaria. Esta sería una trágica pérdida no sólo para Baja California Sur, sino para el conjunto de la diversidad cultural mexicana y mundial, ya que la oasisidad es una prueba viviente de la posibilidad efectiva de vivir sustentablemente en condiciones extremas de aislamiento y aridez. Si los oasis y sus saberes perviven a los embates de la modernización y del neoliberalismo, otorgarán a la sociedad regional, a la academia y a los gobiernos locales y federales, un lugar privilegiado para aprender sobre formas de producir orientadas a la vida y no a la comercialización de bienes agroalimentarios, pero también ofrecen una oportunidad de mitigación y adaptación a los efectos del cambio climático. 
Despoblamiento en el mundo rural, ausencia de expectativas de futuro para nuevas generaciones emigradas o permanentes en sus territorios y la emergencia de espejismos de rentabilidad monetaria en trabajos dentro del sector de servicios, oscurecen la potencialidad del Eden oasiano. Los agroecosistemas tradicionales son modelos sostenibles del uso de los recursos naturales, y posibles palancas para el cambio a un sistema agroalimentario alternativo, que tenga por objeto la calidad y la diversidad de los alimentos, la justa distribución de los mismos, la relocalización de la producción y del consumo, y la conservación de la diversidad cultural y biológica (Tenza et al, 2013).

Son variados y loables los esfuerzos emprendidos para conocer, valorar, conservar y rescatar la oasisidad, pero no han sido suficientes. Quienes estamos interesados en su pervivencia tenemos por delante la tarea de recomponer los equilibrios de tierra y agua en las comunidades, aprender de sus lecciones para la sustentabilidad local, y teniendo como actores principales las comunidades oasianas (las que no han abandonado sus terruños y las que están regresando a ellos) re-crear el otro mundo posible que permite la oasisidad.

\section{Bibliografía}

Arriaga, L. y Rodríguez-Estrella, R. (Eds.) (1997): Los Oasis de la Península de Baja California. Centro de Investigaciones Biológicas del Noroeste. Publicación No. 13. La Paz, BCS, México.

Baegert, J. J. (1989): Noticia de la Península Americana de California, (la. ed. 1772 Mannheim), 2a edición en español, Gobierno del Estado de Baja California Sur, La Paz, México.

BAtTESTI, V. (2005): Jardins au désert. Évolution des pratiques et savoirs oasiens, Jérid tunisien. IRD Éditions, París.

Berkes, F. y Folke, C. (1998): Linking social and ecological systems. Management practices and social mechanisms for building resilience. Cambridge University Press, Cambridge.

Breceda A., Arriaga L. y Coria, R. (1997): "Características socioeconómicas y uso de los recursos naturales", en: Arriaga L. y Rodríguez-Estrella, R. (Eds.), Los oasis de la Península de Baja California. Centro de Investigaciones Biológicas del Noroeste. Publicación No. 13. La Paz, BCS, México.

Cariño, M. (1996): Historia de las Relaciones Hombre/Naturaleza en Baja California Sur, 1500-1940, La Paz, BCS: Centro de Investigaciones Biológicas del Noroeste, UABCS-SEP.

CARIÑo, M. (2001): "La oasisidad, núcleo de la cultura sudcaliforniana" en: 
Gaceta Ecológica, 60, INE, México, pp 57-69.

CariÑo, M. (2007): "Exploraciones y descubrimientos 1533-1678" en: Cariño Olvera, M. y Castorena, L. (Eds.): Sudcalifornia: de sus orígenes a nuestros días. Gob. del Estado de BCS, UABCS-SEP, SIMAC-CONACYT, México, pp 55-85.

CARIÑo, M. y CASTORENA, L. (Eds.) (2007): Sudcalifornia: de sus orígenes a nuestros días, Gob. del Estado de BCS, UABCS-SEP, SIMAC-CONACYT, México.

Cariño, M. y Monteforte, M. (Eds.) (2008): Del saqueo a la conservación: historia ambiental contemporánea de BCS, 1940-2003, SEMARNAT-INE, CONACYT, UABCS, México.

CARIÑ̃, M. (2011): "La identidad oasiana," en: Ortega Santos A. y Molina Aguado, A. (Eds.), Oasis: Agua, Biodiversidad y Patrimonio, Editorial Atrio, España.

Cariño, M., Urciaga, J., Castorena, L., Maya, Y., Wurl, J. y Breceda, A. (2012): "Transformación de los ecosistemas áridos para su uso agrícola en Baja California Sur, México. Un análisis desde la historia ambiental", Historia Agraria, Abril 2012, 56, pp 81-106, Murcia, España.

Cariño, M., Breceda, A., Ortega, A. y Castorena, L. (Eds.) (2013): Evocando al edén. Conocimiento, valoración y problemática del Oasis de Los Comondú, Icaria Editorial, Barcelona.

Cariño, M. y Ortega Santos, A. (Eds.) (2014): Oasis Sudcalifornianos. Para un rescate de la sustentabilidad local, Editorial UGR, Granada, España.

Castrorena, L. y Martínez, A. (2014): "Entre el éxodo y la perseverancia. Patrones socioculturales en la dinámica demográfica del oasis de Los Comondú, 1500-2010", en: Cariño, M., Breceda, A., Ortega, A. y Castorena, L. (Eds.) (2013): Evocando al edén. Conocimiento, valoración y problemática del Oasis de Los Comondú, Icaria Editorial, Barcelona, pp 411-438.

Castrorena Davis, L. (2014): "Prólogo", en: Cariño, M. y Ortega Santos, A. (Eds.), Oasis Sudcalifornianos. Para un rescate de la sustentabilidad local, Editorial UGR, Granada, España, pp 9-13.

Crosby, H. (1992): Los últimos californios. Gobierno del Estado de Baja California Sur. La Paz, BCS, México.

Conagua, (2010),

http://www.conagua.gob.mx/disponibilidad.aspx?n1=3\&n2=62\&n3=94

Ivanova, A., Cariño, M., Ramírez, O. (2002): Comercio y Desarrollo Sustentable en SudCalifornia (siglos XIX y XX). UABCS. SEP, CONACYT, La Paz. LAUREANO, P. (1988): Sahara, giardino sconosciuto, Giuniti, Florencia. 
Ley de Aguas Nacionales (2012): Texto vigente, última reforma publicada DOF 08-06-2012.

LIINAS J. y JIMÉNEZ, M. L. (2004): Arañas de humedales del sur de Baja California, México. Anales del Instituto de Biología. Serie Zoología, 75(2): 283-302.

Martínez-BalboA, A. (1998): La ganadería en Baja California Sur. Gobierno del Estado de Baja California Sur. La Paz, BCS, México.

Maya Y., Coria, R. y Domínguez, R. (1997): "Caracterización de los oasis", en: Arriaga L. y Rodríguez-Estrella R. (Eds.), Los oasis de la Península de Baja California. Centro de Investigaciones Biológicas del Noroeste. Publicación No. 13. La Paz, BCS, México.

Ortega Santos, A. (2013): "Apogeo de la Sociedad Oasiana (1947-2010)" en: Cariño, M. et al. (Eds.) Evocando al edén. Conocimiento, valoración y problemática del oasis de los Comondú, Icaria Editorial, Barcelona, pp 285-316.

MartíneZ, L. P., (2008): "El valor patrimonial universal dels regadius historics valencians: el Palmeral i la Séquia Major d'Elx", en: Tractat de l'aigua. Revista valenciana interdisciplinar de l'aigua, 1, febrero 2008, Valencia, España, pp 72-82.

Tenza, A., Giménez, A., Pérez, I. Martínez, J., Domínguez, W. Noriega, J. y CAstillo, A. L. (2013): "La dinámica del regadío tradicional del Oasis de los Comondú" en: Cariño, M. et al. (Eds.) Evocando al edén. Conocimiento, valoración y problemática del oasis de los Comondú, Icaria Editorial, Barcelona, pp 363-391.

Toledo V. y BarReRA-Bassols, N. (2008): La memoria biocultural, Icaria Editorial, Barcelona, España.

URCIAGA, J. (2008): "La agricultura en Baja California Sur. Una Perspectiva de largo plazo (1900-2005)", en: Cariño, M. y Monteforte M. (Eds.). Del Saqueo a la Conservación. Historia ambiental contemporánea de Baja California Sur, 1940-2003, UABCS, SEMARNAT, INE, CONACYT, La Paz, pp 249-279. 